\title{
Blood DNA Methylation Levels in the WNT5A Gene Promoter Region: A Potential Biomarker for Agitation in Subjects with Dementia
}

\author{
Nobuyuki Kobayashi ${ }^{\mathrm{a}, \mathrm{b}, *}$, Shunichiro Shinagawa ${ }^{\mathrm{b}}$, Tomoyuki Nagata ${ }^{\mathrm{b}}$, Kenji Tagai $^{\mathrm{b}}$, \\ Kazuya Shimada ${ }^{a}$, Azusa Ishii ${ }^{\mathrm{a}}$, Naomi Oka ${ }^{\mathrm{a}}$, Masahiro Shigeta ${ }^{\mathrm{b}}$ and Kazuhiro Kondo ${ }^{\mathrm{a}}$ \\ ${ }^{a}$ Department of Virology, The Jikei University School of Medicine, Tokyo, Japan \\ ${ }^{\mathrm{b}}$ Department of Psychiatry, The Jikei University School of Medicine, Tokyo, Japan
}

Accepted 1 April 2021

Pre-press 3 May 2021

\begin{abstract}
.
Background: Behavioral and psychological symptoms of dementia (BPSD) cause a heavy burden for both patient and caregivers. These symptoms are diverse, and their mechanism is still unclear. Agitation is the most common and difficult to treat among BPSD. In recent years, while changes in DNA methylation levels have been receiving attention as a biomarker of aging and dementia, associations with BPSD have not been examined.

Objective: Focusing on agitation, the objective of the present study was to identify a region where changes in DNA methylation levels are associated with agitation.

Methods: Using genome-wide DNA methylation analysis data for 7 dementia subjects with agitation, 5 dementia subjects without agitation, and 4 normal elderly controls, we determined a signaling pathway in the WNT5A gene promoter region to be associated with agitation. Based on this result, we measured DNA methylation levels in this region for 26 dementia subjects with agitation and 82 dementia subjects without agitation by means of methylation-sensitive high-resolution melting (MS-HRM) analysis.

Results: The WNT5A DNA methylation level in dementia subjects with agitation was significantly lower than in those without agitation $(p=0.001)$. Changes in WNT5A DNA methylation levels were not influenced by age, sex, body mass index, APOE $\varepsilon 4$, medication, or inflammatory cytokines.

Conclusion: Our results suggested an association of agitation with Wnt signaling, in particular with changes in WNT5A DNA methylation levels, which could be a potentially useful biomarker for predicting the appearance of agitation. It may contribute to the elucidation of the mechanism of BPSD.
\end{abstract}

Keywords: Alzheimer's disease, behavioral and psychological symptoms of dementia, dementia, DNA methylation, epigenetics, Wnt signaling pathway, WNT5A

\footnotetext{
${ }^{*}$ Correspondence to: Nobuyuki Kobayashi, Department of Virology, The Jikei University School of Medicine, Tokyo, Japan. Tel.: +81 33433 1111; Fax: +81 35400 1305; E-mail: kobayashin@jikei.ac.jp.
}

\section{INTRODUCTION}

Dementia is widely acknowledged as a public health and social care priority worldwide. It is any decline in cognition due to some changes in the brain that are significant enough to interfere with independent, daily functioning; it is not a single 
disease [1]. In addition to cognitive impairments (e.g., memory disorder, visuospatial disorder, attentional deficit, and executive dysfunction) as its core symptoms, behavioral and psychological symptoms of dementia (BPSD) often occur and affect $90 \%$ of subjects diagnosed with dementia [2]. BPSD include delusions, hallucinations, agitation, aggression, depression/dysphoria, anxiety, elation/euphoria, apathy/indifference, disinhibition, irritability/lability, aberrant motor behavior, sleep and nighttime behavior disorders, appetite and eating changes, and other behavioral disorders [3, 4] causing suffering for both patients and caregivers, and they increase the risk of dementia subjects being admitted to hospital [5, 6]. Genetic, biological, and socio-psychological backgrounds are thought to have an influence in BPSD appearance [7], but up until now, it has been difficult to predict them so their mechanism needs to be elucidated.

In the clinical treatment of BPSD, it is recommended that non-pharmacological interventions are first tried, and if there is difficulty in treatment, pharmacological methods are tried $[2,8]$ However, there is a greater possibility of drug therapy causing severe adverse reactions in elderly people. When BPSD appear, they require inpatient treatment in many cases. Therefore, from the treatment aspect, the development of a biomarker for use in predicting and preventing BPSD and as an indicator in treatment is much needed.

In previous research aiming to identify a BPSD biomarker, we reported that among BPSD, plasma brain-derived neurotrophic factor (BDNF) levels were associated with aggression in Alzheimer's disease (AD), the most common cause of dementia [9]. We also demonstrated that methylation in the BDNF promoter region, which influences BDNF expression, was significantly altered in $\mathrm{AD}$ as compared with elderly normal controls (NC) [10].

BPSD are diverse and among them, agitation is common in elderly people with dementia and difficult to treat [11]. In AD, it most frequently appears together with irritability and aggression [12]. Agitation poses a risk for patients themselves as well as other patients and caregivers, whom it subjects to extreme stress, and is a major challenge for clinicians $[13,14]$.

In recent years, several studies have reported changes in DNA methylation levels in the blood and brain of dementia subjects and they are considered to exert an influence in the development of dementia [15]. We previously reported that, in AD patients, there were major changes in blood DNA methylation levels as compared with NCs in various gene regions other than the BDNF promoter region [16]. We also demonstrated that, compared to NCs, changes in blood DNA methylation levels in the COASY gene promoter region in $\mathrm{AD}$ patients were significantly greater $[17,18]$. At minimum, this means that changes in blood DNA methylation levels have the potential to be a useful diagnostic biomarker for $\mathrm{AD}$

Changes in DNA methylation levels can be due to environmental factors [19]. Therefore, we hypothesized that stress and socio-psychological influences might bring about changes in DNA methylation levels in various gene promoter regions in the brains of dementia subjects and contribute to the development of BPSD.

In view of the above, focusing on agitation, the objective of the present study was to identify a region of DNA methylation associated with it. Although we thought that DNA methylation levels in the blood and brain might not necessarily be matched, a previous study had found correlations of changes in DNA methylation levels due to aging among different organs [20] and another had demonstrated similar alterations in DNA methylation in the blood and in the brain [21]. Therefore, we thought that DNA methylation levels in the blood could reflect DNA methylation levels in the brain and in the present study, examined a correlation between blood DNA methylation levels and agitation. Blood DNA methylation levels could be a simple and non-invasive biomarker of BPSD and would also be useful for clarifying the mechanism of BPSD.

Wnt signaling contributes to development by regulating stem cells [22]. In Wnt signaling, there is known to be a canonical cascade dependent on $\beta$ catenin and a non-canonical cascade dependent on Wnt/planar cell polarity (PCP) signaling [23] and the $\mathrm{Wnt} / \mathrm{Ca}^{2+}$ pathway $[24,25]$. WNT5A is a $\beta$-cateninindependent ligand that is receiving attention as a therapeutic target for controlling cancer and inflammation [26]. In addition, it has been reported that WNT5A production is regulated by cytokines such as interleukin- 1 beta (IL-1 $\beta$ ) and tumor necrosis factoralpha (TNF- $\alpha)[27,28]$. In view of this, we considered it necessary to examine whether there was an association between changes in Blood DNA methylation levels (and mRNA) and inflammatory cytokines. It was previously reported that neuroinflammation and inflammatory cytokines were involved in $\mathrm{AD}$ and other neurodegenerative diseases [29] and that they 
were associated with neuropsychiatric symptoms in dementia [30]. Furthermore, in recent years, attention has been focused on an association with peripheral inflammation and neuroinflammation and it is considered that that obesity, diabetes and other chronic systemic inflammatory diseases induce neuroinflammation, increasing the risk of $\mathrm{AD}$ [31]. Therefore, in the present study, we also measured blood cytokine levels and analyzed their effects.

\section{MATERIALS AND METHODS}

\section{Ethics statement}

The study was approved by the Ethics Committee of the Jikei University School of Medicine and written informed consent was obtained from all individuals. For participants whose capacity to consent was compromised, caregivers who were the spouse or a relative within the second degree consented on their behalf as a substitute decision-maker but only when the patient had agreed to participate. The present study was performed in accordance with the principles of the Declaration of Helsinki and the Ethical Guidelines for Medical and Health Research Involving Human Subjects in Japan.

\section{Genome-wide DNA methylation analysis}

According to the same method as in our previous study [16], blood DNA from 7 patients with AD and 1 patient with $\mathrm{VaD}$ was bisulfite converted and DNA methylation analysis was conducted using Infinium MethylationEPIC BeadChip (Illumina). Adding the results from the analysis of $4 \mathrm{AD}$ patients and 4 normal elderly controls (NCs) that we carried out using Infinium HumanMethylation450 BeadChip (Illumina) previously [16], the analysis in the present study was for 12 subjects with dementia and 4 NCs. In addition, we further divided the dementia group according to BPSD into a subgroup of 7 patients with agitation and one of 5 patients without agitation.

\section{Functional and pathway enrichment analyses}

For genes with significant differences in methylation levels, we determined functional and biological processes through Gene Ontology (GO) annotation and Kyoto Encyclopedia of Genes and Genomes (KEGG) pathway analyses using The Database for Annotation, Visualization and Integrated Discovery (DAVID) v6.8 (https://david.ncifcrf.gov/home.jsp).

\section{Participants}

The participants for the study to compare DNA methylation levels between with and without agitation were 108 patients who had visited Aira-no-mori Hospital (Aira-gun, Kagoshima Prefecture), been diagnosed with dementia and were under treatment. Among them were 63 subjects whose data was used in our previously published research [18]. The breakdown of the present subjects was 67 with $\mathrm{AD}, 27$ with vascular dementia (VaD), and 6 with dementia with Lewy bodies (DLB). Other types of dementia subjects included were 2 semantic variant primary progressive aphasia (svPPA) patients, one progressive supranuclear palsy (PSP) patient, and 5 idiopathic normal pressure hydrocephalus (iNPH) patients. Among the total of 108 subjects, we could not sample RNA for 5 subjects (AD $n=4, \mathrm{VaD}$ $n=1)$. AD was diagnosed based on the criteria of the US National Institute of Neurological and Communicative Disorders and Stroke and those of the Alzheimer's Disease and Related Disorders Association (NINCDS-ADRDA) [32]. VaD was diagnosed according to the criteria of the National Institute of Neurological Disorders and Stroke and Association Internationale pour la Recherche et l'Enseignement en Neurosciences (NINDS-AIREN) [33, 34]. DLB was diagnosed according to the fourth consensus report of the DLB Consortium in 2017 [35]. svPPA was diagnosed according to the International behavioral variant frontotemporal dementia (FTD) Criteria Consortium (FTDC) revised criteria [36] and classification guidelines for primary progressive aphasia [37]. PSP was diagnosed according to the criteria of the National Institute of Neurological Disorders and those of the Society for PSP (NINDS-SPSP) [38]. iNPH was diagnosed according to the diagnostic criteria for iNPH in the Japanese iNPH guidelines [39].

The Mini-Mental State Examination (MMSE) was administered for all of the patient groups by expert clinical psychologists [40]. The severity of BPSD was evaluated with the Neuropsychiatric Inventory ([NPI]: scores range from 0 to 120 , where a higher score reflects a more severe neuropsychiatric condition) [41]. However, education level was not known for 1 subject (AD). Also, a MMSE score was missing for 23 subjects ( $\mathrm{AD} n=14, \operatorname{VaD} n=5$, DLB $n=1$, svPPA $n=2$, iNPH $n=1)$ and a NPI score was missing for 4 subjects (AD $n=2, \mathrm{VaD}$ $n=2$ ) due to difficulty in performing the respective tests. 
GGGCCACAGT TGAGTAGTGG TACATTTTTT TCACCCTCTT GTGAAGAATT TCTTTTTATT

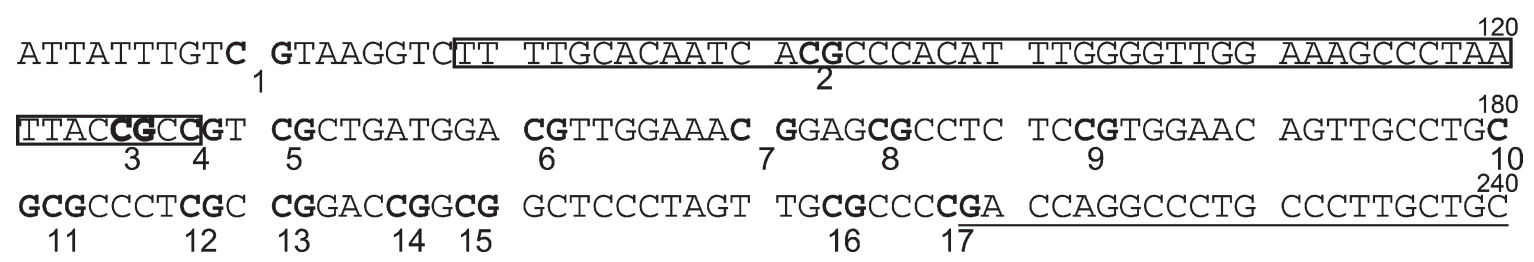

Fig. 1. WNT5A upstream sequence corresponding to PCR amplification region. Underlined parts indicate primer-binding sites. Boxes indicate probe-binding sites. CpGs are indicated as bold characters. The 3rd CpG is the target site of the Illumina Infinitum HD Methylation Assay.

\section{APOE genotyping}

Genomic DNA was extracted from peripheral blood cells using QIAamp DNA Blood Midi Kit (Qiagen). According to the same procedure as used previously, APOE genotypes (rs429358 and rs7412) were determined by allelic discrimination on an Applied Biosystems 7300 real-time PCR System (Thermo Fisher Scientific) [18].

\section{Methylation-sensitive high-resolution melting (MS-HRM) analysis}

According to the same method as in our previous research, DNA methylation levels in the WNT5A gene promoter region were measured by MS-HRM analysis [18]. Brief details are given below.

Each genomic DNA sample was first bisulfiteconverted using an EpiTect Plus DNA Bisulfite Kit (Qiagen). In order to measure DNA methylation levels in the WNT5A gene promoter region, we designed primers with Methyl Primer Express Software v1.0 (Thermo Fisher Scientific) in a region including the sequences of the probe (Target ID cg24942186) used with the Illumina Infinitum HD Methylation Assay. The probe (Target ID cg24942186) is within $200 \mathrm{bp}$ of the transcription start site of WNT5A mRNA (GenBank accession number NM_003392, Gene ID: 7474). The primers were as follows: WNT5A forward primer, 5'-GGGTTATAGTTGAG TAGTGGTATAT-3', human $C O A S Y$ reverse primer, 5'-ACAACAAAAACAAAACCTAATC- $3^{\prime}$. The amplification size was $240 \mathrm{bp}$ and included $17 \mathrm{CpG}$ sites (Fig. 1).

DNA derived from DNMT1 and DNMT3B double knock-out HCT116 cells (Takara Bio) and DNA derived from these cells that had been methylated with CpG methylase were bisulfited. These busulfited DNAs were then mixed and used to produce a calibration curve for methylation rates of $100 \%, 75 \%$,
$50 \%, 25 \%, 5 \%$, and $0 \%$. MS-HRM was performed with the Applied Biosystems QuantStudio 12K Flex Real-Time PCR System (Thermo Fisher Scientific). Using the bisulfited control DNA values, the calibration curve was obtained by regression using a cubic function and DNA methylation levels of samples were quantified. The aligned melt curves and calibration curve are shown in Fig. 2A and B.

\section{Real-time RT-PCR}

Whole blood was sampled in PAXgene RNA Tubes (Becton, Dickinson and Company) and stored according to the attached protocol. After thawing the stored blood, RNA was extracted using a PAXgene Blood miRNA Kit (Qiagen). cDNA was synthesized from total RNA using a PrimeScript RT reagent Kit (Takara Bio) to produce a concentration of about $50 \mathrm{ng} / \mu \mathrm{L}$. WNT5A mRNA and $A C T B$ mRNA were quantified by real-time PCR with an Applied Biosystems 7300 real-time PCR System (Thermo Fisher Scientific). Amplifications were performed in duplicate in a total volume of $25 \mu \mathrm{l}$ containing $12.5 \mu \mathrm{L}$ Premix Ex Taq (Takara Bio, Inc.), $0.225 \mu \mathrm{L}$ forward primer $(100 \mu \mathrm{M}), 0.225 \mu \mathrm{L}$ reverse primer $(100 \mu \mathrm{M}), 0.625 \mu \mathrm{L}$ TaqMan probe $(10 \mu \mathrm{M}), 0.5 \mu \mathrm{L}$ Rox reference dye, $8.925 \mu \mathrm{L}$ PCR-grade water, and $2 \mu \mathrm{L}$ cDNA. The primers and probes used were as follows: WNT5A forward primer, 5'-CCAAGGGCTCCTACGAGAGT3'; WNT5A reverse primer, 5'-CAGGTTGTACACC GTCCTGC-3; WNT5A probe, 5'-FAM-TGAACC TGCACAACAACGAGGCCGG-TAMRA-3'; $A C$ $T B$ forward primer, 5'-CCCTGGCACCCAGCAC A-3'; ACTB reverse primer, 5'-AGCCGCCGATCC ACACG-3; and $A C T B$ probe, 5'-FAM-ATCAAGA TCATTGCTCCTCCTGAGCGCA-TAMRA- $3^{\prime}$. The reaction started with an initial denaturation step at $95^{\circ} \mathrm{C}$ for $30 \mathrm{~s}$, followed by 45 cycles of $5 \mathrm{~s}$ at $95^{\circ} \mathrm{C}$ and $31 \mathrm{~s}$ at $60^{\circ} \mathrm{C}$. Data were analyzed with Sequence 
A

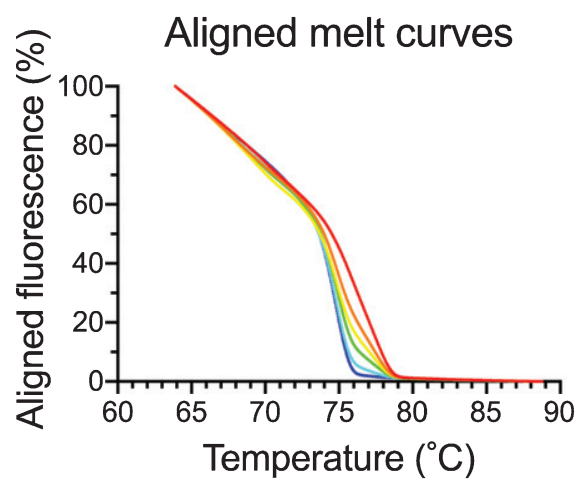

$\mathrm{B}$

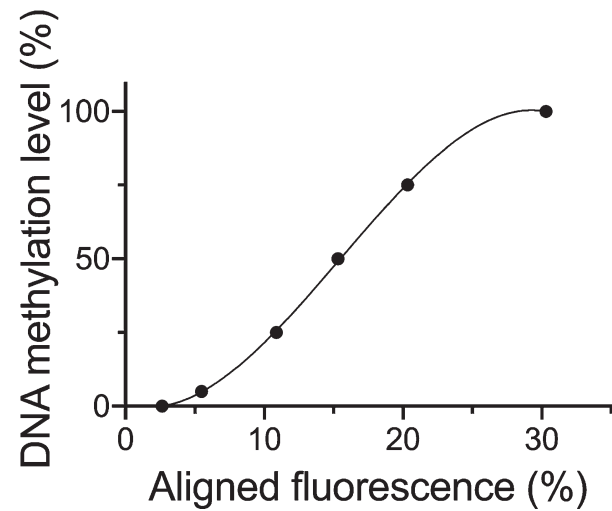

Fig. 2. Aligned melt curves and calibration curve. This shows aligned melt curves (A) and the calibration curve (B) used in MS-HRM analysis for bisulfited DNA. 100\%, 75\%, 50\% 25\%, 5\% and 0\% (control) bisulfited DNA are indicated by the red, orange, yellow, green, light blue and blue lines, respectively.

Detection Software version 1.4 (Thermo Fisher Scientific).

\section{Enzyme-linked immuno sorbent assay (ELISA)}

Serum L- $1 \beta$ and TNF- $\alpha$ concentrations were measured using the Quantikine HS ELISA, Human IL-1 $\beta / I L-1 F 2$ Immunoassay and Human TNF- $\alpha$ Immunoassay (R\&D Systems) according to the attached protocol. Referring to the attached protocol, the sensitivity range for IL- $1 \beta$ for 25 assays was $0.014-0.063 \mathrm{pg} / \mathrm{mL}$ and the TNF- $\alpha$ sensitivity range for 23 assays was $0.011-0.049 \mathrm{pg} / \mathrm{mL}$. The optical density $(450 \mathrm{~nm})$ after the color reaction was measured using a TriStar LB941-vTi Microplate Reader (Berthold Technologies).

\section{Statistical analysis}

Screening in the genome-wide DNA methylation analysis was carried out using Welch's $t$-test. The Shapiro-Wilk test was used to assess the normality of data. The Mann-Whitney U test was used for two-group comparisons. Multiple-group comparisons of non-parametric data were conducted using the Kruskal-Wallis test and the Dunn-Bonferroni correction was used for subsequent testing as needed. Sex and APOE genotype were compared using the Fisher's exact test. Multiple linear regression analysis was then conducted with WNT5A DNA methylation levels as the dependent variable, and age, sex, BMI, years of schooling, disease duration, MMSE score, NPI score, and $A P O E \& 4$ carrier as forced entry variables. Spearman's rank correlation coefficients were used to investigate correlations between two individual data. $p<0.05$ was considered statistically significant.

Statistical analysis was conducted using Excel for Mac 16.43 (Microsoft), SPSS Statistics 21.0 for Windows (IBM) and Prism 8 for macOS (GraphPad Software).

\section{RESULTS}

\section{Screening using genome-wide DNA methylation analysis}

A comparison of 485,577 DNA methylation sites for the 7 dementia subjects with agitation and the 5 without revealed significant changes for 11,797 sites. Among them, there were significant differences between the 7 dementia subjects and 4 NCs for 1,772 sites. These DNA methylation sites were present in $\mathrm{CpG}$ islands and 286 were in known gene regions with GenBank accession numbers. We conducted GO analysis to clarify the functions associated with these 286 genes. Table 1 shows the top 20 GO terms in the results. Table 2 shows 7 pathways obtained through KEGG pathway analysis.

From these results we extracted the Wnt signaling pathway as the common signaling pathway. Among the genes involved in the Wnt signaling pathway, 9 showed significant changes, which were LDL receptor related protein 5 (LRP5), WNT inhibitory factor 1 (WIF1), Wnt family member $5 \mathrm{~A}$ (WNT5A), Wnt family member 9A (WNT9A), nemo like kinase (NLK), nuclear factor of activated $\mathrm{T}$ cells 1 (NFATC1), phospholipase C beta 3(PLCB3), protein kinase cAMP-activated catalytic subunit 
alpha (PRKACA), and transducin beta like $1 \mathrm{X}$ linked receptor 1 (TBL1XR1). When we focused on $W N T 5 A$, the probe id where a significant difference was observed between with and without agitation was cg24942186. This target site was within $200 \mathrm{bp}$ of the transcription start site (TSS) in the CpG island and we considered that this site was in the promoter region. We measured methylation levels in a region

Table 1

Top 20 GO terms

\begin{tabular}{lc}
\hline GO term & $\begin{array}{c}\text { Enrichment } \\
\text { factor } \\
(-\log 10 p \text {-value })\end{array}$ \\
\hline $\begin{array}{l}\text { homophilic cell adhesion via plasma } \\
\text { membrane adhesion molecules }\end{array}$ & 4.98 \\
calcium ion binding & 4.13 \\
protein kinase A regulatory subunit binding & 2.73 \\
myeloid cell differentiation & 2.18 \\
antigen processing and presentation of & 2.06 \\
$\quad$ exogenous peptide antigen via MHC class & \\
I, TAP-independent & \\
mRNA processing & 2.05 \\
heart development & 2.00 \\
nucleus & 1.96 \\
canonical Wnt signaling pathway & 1.95 \\
MHC class I protein complex & 1.91 \\
antigen processing and presentation of & 1.91 \\
$\quad$ peptide antigen via MHC class I & \\
embryonic digit morphogenesis & 1.89 \\
protein binding & 1.83 \\
cellular response to epinephrine stimulus & 1.81 \\
cell proliferation & 1.79 \\
cell adhesion molecule binding & 1.78 \\
protein domain specific binding & 1.75 \\
protein kinase A catalytic subunit binding & 1.70 \\
protein homodimerization activity & 1.63 \\
Wnt signaling pathway, calcium modulating & 1.60 \\
pathway & \\
\hline
\end{tabular}

including this site as WNT5A DNA methylation levels in dementia subjects with and without agitation.

\section{Participant characteristics}

We divided the 108 dementia subjects into two groups by presence or absence of agitation/aggression according to the NPI subscale; where we determined that agitation/aggression was present for a NPI agitation/aggression subscale score of 1 or above and absent for a score of 0 . There were 26 patients with agitation/aggression (taken as "agitation" in present study) and 82 with no agitation/aggression (taken as "no agitation"). Furthermore, regarding numbers of subjects with agitation/aggression in each disease group, there were 16 for $\mathrm{AD}, 7$ for $\mathrm{VaD}, 1$ for $\mathrm{DLB}$, 1 for PSP, and 1 for iNPH. There was no significant difference in proportions of agitation/aggression according to disease group $(p=0.560)$. The patient characteristics for the agitation and no agitation groups are shown in Table 3. There was no significant difference between the groups for age, sex, body mass index (BMI), duration of disease, MMSE

Table 2

KEGG pathway analysis

\begin{tabular}{lc}
\hline Pathway & $\begin{array}{c}\text { Enrichment factor } \\
(-\log 10 p \text {-value })\end{array}$ \\
\hline Wnt signaling pathway & 2.79 \\
Viral myocarditis & 1.89 \\
HTLV-I infection & 1.67 \\
p53 signaling pathway & 1.65 \\
Pathways in cancer & 1.30 \\
Circadian entrainment & 1.18 \\
Amoebiasis & 1.04 \\
\hline
\end{tabular}

Table 3

Participant characteristics

\begin{tabular}{|c|c|c|c|c|}
\hline & Total & No agitation & Agitation & $p$ \\
\hline$n$ & 108 & 82 & 26 & \\
\hline Age (y) median (IQR) [min-max] & $86.0(83.0-89.0)$ [59-94] & $86.0(83.0-89.0)$ [59-93] & $85.0(81.5-90.3)$ [69-94] & 0.821 \\
\hline Female: male (\%) & $50.0: 50.0$ & $52.4: 47.6$ & 42.3:57.7 & 0.500 \\
\hline BMI median (IQR) [min-max] & $21.0(19.1-23.2)[14.4-34.2]$ & $20.9(19.0-23.1)[14.4-34.2]$ & $21.4(19.6-23.3)$ [16.6-28.0] & 0.612 \\
\hline $\begin{array}{l}\text { Education (y) median (IQR) } \\
{[\text { min-max }]^{\mathrm{a}}}\end{array}$ & $9.0(9.0-12.0)[0-16]$ & $9.0(9.0-12.0)[0-16]$ & $9.0(9.0-10.5)[6-14]$ & 0.190 \\
\hline $\begin{array}{l}\text { Duration of disease (y) median } \\
\text { (IQR) [min-max] }\end{array}$ & $2.0(0.3-4.0)[0-15]$ & $2.0(0.3-4.5)[0-15]$ & $2.0(0.3-4.0)[0-6]$ & 0.571 \\
\hline $\begin{array}{l}\text { MMSE score median (IQR) } \\
{[\text { min-max }]^{\mathrm{b}}}\end{array}$ & $11.0(6.5-14.5)[0-26]$ & $11.0(6.5-15.0)[0-26]$ & $9.0(4.0-13.0)[0-20]$ & 0.322 \\
\hline $\begin{array}{l}\text { NPI total score median (IQR) } \\
{[\text { min-max }]^{\mathrm{c}}}\end{array}$ & $4.0(0.0-16.0)[0-56]$ & $2.0(0.0-8.0)[0-36]^{\mathrm{d}}$ & $19.0(10.5-36.0)[2-56]^{\mathrm{e}}$ & 0.000 \\
\hline$A P O E \varepsilon 4$ carrier $(\%)$ & $34(31.5)$ & $23(28.0)$ & $11(42.3)$ & 0.132 \\
\hline $\begin{array}{l}\text { WNT5A DNA methylation level } \\
(\%) \text { median (IQR) [min-max] }\end{array}$ & $4.9(1.9-9.5)[-2.2-24.7]$ & $6.6(2.5-10.0)[-1.1-24.7]$ & $2.2(0.7-6.5[-2.2-19.5]$ & 0.001 \\
\hline
\end{tabular}

IQR, interquartile range. ${ }^{\mathrm{a}} n=107 ;{ }^{\mathrm{b}} n=85 ;{ }^{\mathrm{c}} n=104,{ }^{\mathrm{d}} n=79 ;{ }^{\mathrm{e}} n=25$. 


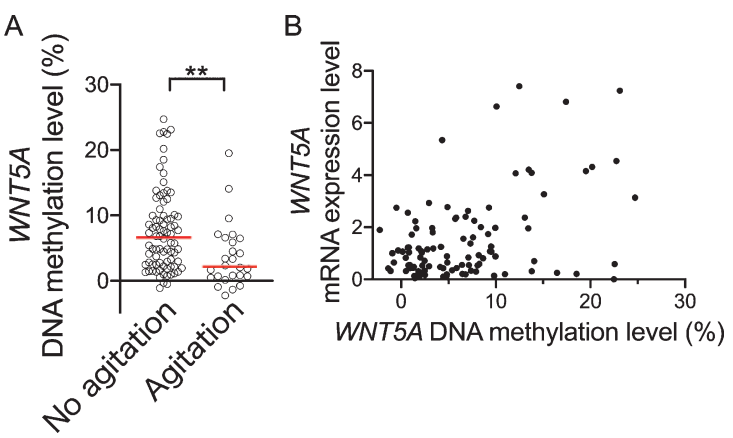

Fig. 3. Comparison of WNT5A DNA methylation levels between with/without agitation according to NPI score. A) Shows WNT4A DNA methylation levels for dementia with/without agitation. B) Shows correlation between WNT5A DNA methylation levels and mRNA expression level. Horizontal lines indicate medians. ${ }^{* *} p<0.01$.

total score, or $A P O E \varepsilon 4$ positive rate. However, the NPI total score was significantly higher in the agitation group than in the no agitation group $(p<0.0001)$ and WNT5A DNA methylation levels were significantly lower in the former $(p=0.001$, Fig. 3). Also, on comparing between the agitation and no agitation groups, there were no significant differences in the proportions of the dementia diagnosis groups $(p=0.560)$. No significant differences in WNT5A DNA methylation levels were observed among patients with the various types of dementia $(p=0.276)$. There were also no significant differences in WNT5A DNA methylation levels between with and without antihypertensive medication, anti-hyperlipidemia drugs, anti-inflammatories, anticoagulant/antiplatelet agents, anti-dementia drugs, antipsychotics, antidepressants, anxiolytics, or antiepileptic medication $(p=0.263$, medication rate $57.4 \% ; p=0.693$, medication rate $8.3 \% ; p=0.731$, medication rate $6.5 \% ; p=0.373$, medication rate $24.1 \% ; p=0.914$, medication rate $11.1 \% ; p=0.225$, medication rate $86.1 \% ; p=0.512$, medication rate $79.6 \% ; p=0.400$, medication rate $1.9 \% ; p=0.236$, medication rate $14.8 \%$, respectively).

\section{Multiple linear regression analysis}

To determine whether WNT5A DNA methylation levels were affected by BPSD and other factors, multiple linear regression analysis was conducted with age, sex, BMI, education, duration of disease, MMSE total score, NPI total score, and presence/absence of APOE $\varepsilon 4$ as forced entry variables and WNT5A DNA methylation level as the dependent variable (Table 4). Age, sex, obesity, and education are known
Table 4

Factors associated with WNT5A DNA methylation levels according to multiple linear regression analysis

\begin{tabular}{lccc}
\hline Variables & $B$ & S.E.M. & $p$ \\
\hline Age & 0.036 & 0.103 & 0.725 \\
Sex & 1.549 & 1.446 & 0.288 \\
BMI & -0.026 & 0.210 & 0.902 \\
Education & 0.455 & 0.310 & 0.146 \\
Duration of disease & -0.150 & 0.238 & 0.530 \\
MMSE score & 0.140 & 0.125 & 0.267 \\
NPI total score & -0.125 & 0.054 & 0.023 \\
APOE $\varepsilon 4$ carrier & -0.073 & 1.622 & 0.964 \\
\hline
\end{tabular}

$n=81, R^{2}=0.162$, ANOVA $p=0.104$.

Table 5

Significant correlation between WNT5A DNA methylation levels and agitation

\begin{tabular}{lccc}
\hline NPI subscales & $\rho$ & $p$ & $n$ \\
\hline Delusions & 0.108 & 0.269 & 107 \\
Hallucinations & -0.105 & 0.281 & 108 \\
Agitation/Aggression & -0.301 & 0.002 & 108 \\
Depression/Dysphoria & -0.077 & 0.428 & 108 \\
Anxiety & -0.109 & 0.266 & 107 \\
Elation/Euphoria & -0.157 & 0.106 & 107 \\
Apathy/Indifference & -0.140 & 0.151 & 107 \\
Disinhibition & 0.068 & 0.484 & 107 \\
Irritability/Lability & -0.134 & 0.170 & 107 \\
Aberrant motor behavior & -0.081 & 0.411 & 106 \\
Sleep and nighttime behavior disorders & -0.083 & 0.396 & 106 \\
Appetite and eating changes & -0.139 & 0.153 & 107 \\
12 item score & -0.228 & 0.020 & 104 \\
10 item score & -0.246 & 0.011 & 105 \\
\hline
\end{tabular}

risk factors for dementia and BMI was used as an indicator of obesity, a known risk factor for lifestyle diseases. There was only a significant association of WNT5A DNA methylation level with NPI total score.

\section{Correlation between WNT5A DNA methylation levels and agitation}

As we considered that WNT5A DNA methylation level could be affected by other types of BPSD as well, we examined associations not only with total score but also with subscale scores and show the results in Table 5. Besides total score, there was only a significant negative correlation for agitation/aggression with WNT5A DNA methylation levels $(p<0.01)$. Differences for other NPI subscales were not significant.

\section{WNT5A mRNA expression in blood}

Although there was a significant positive correlation between blood WNT5A mRNA and WNT5A DNA methylation levels $(\rho=0.271, p=0.006, n=103$, 
A

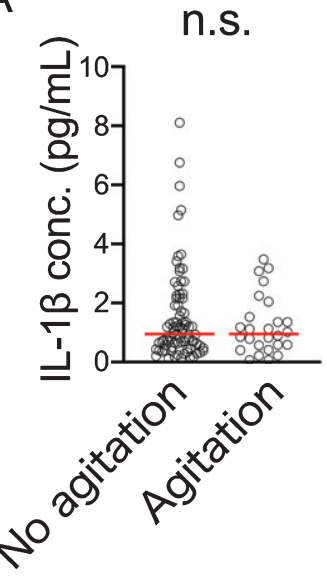

$\mathrm{B}$

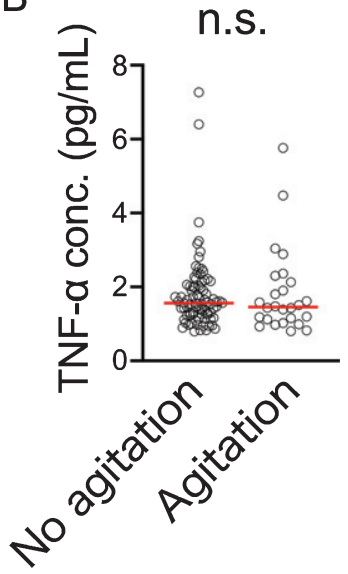

Fig. 4. Blood IL-1 $\beta$ (A) and TNF- $\alpha$ (B) concentrations compared by presence/absence of agitation according to NPI score. Horizontal lines indicate medians n.s., not significant.

Fig. 3B), blood WNT5A mRNA was not significantly correlated with agitation/aggression subscale score $(\rho=-0.01, p=0.922, n=103)$. In addition, in a comparison by presence/absence of agitation/aggression, no significant differences in WNT5A mRNA were observed $(p=0.884, n=103)$.

\section{Involvement of blood inflammatory cytokines in agitation}

We measured serum IL- $1 \beta$ and TNF $\alpha$ levels in the dementia subjects and conducted a comparison for with and without agitation but there was no significant difference between them (Fig. 4A, B). In addition, there were no significant correlations between blood WNT5A DNA methylation levels or mRNA levels and these cytokines (IL-1 $\beta$ : versus WNT5A DNA methylation level, $\rho=0.127, p=0.190, n=108$, versus WNT5A mRNA level, $\rho=-0.003, p=0.976$, $n=103$; TNF- $\alpha$ : versus WNT5A DNA methylation level, $\rho=0.177, p=0.067, n=108$, versus WNT5A mRNA level, $\rho=-0.047, p=0.635, n=103)$.

\section{DISCUSSION}

In this study, we searched for a biomarker associated with agitation, which among BPSD, is difficult to manage clinically. We conducted a comprehensive analysis of DNA methylation using a small number of dementia patient blood samples. We also divided the dementia subjects into two groups, one with agitation and the other without, and compared them.
Further, for genes with CG sites in which a significant difference with NCs was observed, the results of GO analysis and KEGG pathway analysis suggested the involvement of the Wnt signaling pathway in agitation (Tables 1 and 2). To substantiate this, we analyzed samples from 108 dementia subjects (26 with agitation, 82 without) and found that WNT5A DNA methylation levels were significantly lower in the group with agitation than in the group without agitation (Fig. 3A and Table 3 ).

We examined age, sex, BMI, education, duration of disease, MMSE total score, NPI total score, and $A P O E \varepsilon 4$ as factors that could influence WNT5A DNA methylation levels in multiple linear regression analysis but did not find any significant associations other than that with NPI total score (Table 4). In view of this finding for NPI total score, we examined associations with individual subscales but the only one having a significant association with WNT5A DNA methylation levels was agitation/aggression (Table 5). These results indicate the possibility that a decrease in WNT5A DNA methylation levels is associated with the appearance of agitation.

Among the NPI subscales, agitation/aggression had been considered to be the same component as irritability/lability [42] but the results of the present study suggested that agitation/aggression and irritability/lability have different mechanisms because no association was noted between WNT5A DNA methylation levels and irritability/lability. They also indicate the possibility that among BPSD, WNT5A DNA methylation levels could be a useful biomarker specifically for agitation/aggression. In addition, the NPI agitation/aggression subscale mainly consists of behaviors indicating refusal of care, and the irritability/lability subscale mainly consists of emotional problems; therefore, there is strictly a distinction between the two.

We previously reported that plasma BDNF levels were associated with aggression in $\mathrm{AD}$ [9] but in the analysis in the present study, we did not detect changes in DNA methylation levels for $B D N F$ as a site associated with agitation/aggression. As a reason, our previously reported observation that compared to NCs, DNA methylation levels in the $B D N F$ promoter region were significantly higher in AD [10] suggests that $B D N F$ DNA methylation levels are not directly associated with agitation/aggression but with $\mathrm{AD}$ itself and that plasma BDNF levels are regulated by factors other than DNA methylation.

Furthermore, there was a significant positive association between WNT5A DNA methylation levels and 
mRNA (Fig. 3B). Generally, DNA methylation in a promoter region interferes with binding with RNA polymerase, inhibiting transcription [43, 44], but the results of the present study are inconsistent with this observation. Increases in DNA methylation levels have been found to enhance gene expression [45] and the results of the present study suggest that DNA methylation in the $\mathrm{CpG}$ site we selected has this role.

However, since there was no significant association between WNT5A mRNA levels and agitation/aggression subscale, we considered that blood WNT5A mRNA was not directly involved in the appearance of agitation/aggression. In the present study, brain WNT5A DNA methylation levels and mRNA levels were unknown but as it has been predicted that blood DNA methylation levels and brain DNA methylation levels are associated [20, 21], we think that brain WNT5A changes are involved in the appearance of agitation.

In the present study, we examined whether changes in blood DNA methylation levels and mRNA were due to inflammatory cytokines like IL- $1 \beta$ and TNF- $\alpha$ but did not observe any significant correlations. IL-1 $\beta$ and TNF- $\alpha$ seem to have a WNT5A promoting action $[27,28]$, but the lack of an association with IL-1 $\beta$ or TNF- $\alpha$ suggested that these blood cytokines had no influence in the change in WNT5A DNA methylation levels and mRNA levels in this study. This also suggests that the change in WNT5A DNA methylation levels was not due to a systemic inflammation but a neuroinflammation in the brain.

For with and without agitation, as we did not observe a significant difference in serum IL-1 $\beta$ and TNF- $\alpha$ levels (Fig. 4A, B), we considered that, at minimum, serum levels of inflammatory cytokines like IL-1 $\beta$ and TNF- $\alpha$ were not involved in the appearance of agitation. However, as the involvement of neuroinflammation was not examined in the present study, it is possible that it is involved in agitation. Based on the foregoing, appearance of agitation and the related changes in WNT5A DNA methylation could arise independently of peripheral inflammation so it will be necessary to examine the influence of neuroinflammation in future studies. Wnt signaling plays an important role in embryogenesis and is involved in the differentiation and development of the central nervous system [46, 47]. Further, Wnt signaling molecules are much expressed in the adult brain including the hippocampus and are involved in synapse maintenance and function [48] as well as in dopaminergic neuron formation and nerve regeneration [49].
Among Wnt signaling molecules, WNT5A plays an important role in the transcriptional activation pathway for Wnt and calcium signaling in a $\beta$ catenin-independent manner [24, 25], it is involved in activation of calcium/calmodulin-dependent kinase II (CaMKII) and glutamate receptors and regulates the accumulation and function of excitatory postsynaptic regions of the mature central nervous system [48]. Based on the results of this study, we considered that methylation of WNT5A gene promoter is involved in the appearance of agitation by disrupting these regulating functions. Therefore, for dementia subjects with agitation, this suggests that if WNT5A gene expression could be normalized by increasing WNT5A methylation, it could be a useful treatment. However, it is not clear whether Wnt signaling is an important agitation/aggression pathway for diseases other than dementia and to clarify this further research will be needed.

The mechanism of appearance of BPSD has not been sufficiently elucidated but our findings could be a step towards remedying this and thinking about their clinical application, WNT5A methylation could be a potentially useful biomarker for assessing treatment effects and care.

As limitations of the present study, first, changes in methylation were not evaluated longitudinally. Thus, if agitation resolved through treatment, we cannot know whether WNT5A methylation would return to the original levels or remain unchanged. This is an issue to be addressed in the future. Second, changes in WNT5A mRNA in the brain could not be evaluated. However, agitation is a symptom that changes, and it would be difficult to directly see corresponding changes in mRNA. Third, in this research we did not conduct a detailed assessment of genetic sociopsychological or other background factors, except for APOE genotyping. Therefore, we do not know if these factors thought to be involved in the appearance of BPSD would have any specific effects on the DNA methylation levels. Fourth, in the present study, since we examined dementia diseases collectively and it was not possible to carry out an examination of the diseases individually due to the small numbers, we were unable to clarify if there was an influence of disease breakdown. However, as we did not observe a significant difference in a comparison of the diseases, we considered it unlikely that the breakdown of diseases affected the results.

In conclusion, in the present study, we identified changes in WNT5A DNA methylation levels as a factor involved in the appearance of agitation in 
dementia subjects. We consider the possibility of changes in WNT5A methylation levels being a clinically useful biomarker for agitation and that it will also contribute to the elucidation of the mechanism of BPSD. We also consider that the pathway by which agitation occurs could be a target for its prevention and treatment in the future.

\section{ACKNOWLEDGMENTS}

The present work was supported by Japan Society for the Promotion of Science (JSPS) KAKENHI (grant number 17K10318, 17K10317), Mitsui Life Social Welfare Foundation and Private University Research Branding Project from the Ministry of Education, Culture, Sports, Science and Technology (MEXT). The funders were not involved in the design of the study or conducting it; in the collection, management, analysis, and interpretation of the data; or in the preparation, review and approval of the manuscript. Also, we would like to thank Mr. Alexander Cox for editorial assistance with the manuscript.

Authors' disclosures available online (https:// www.j-alz.com/manuscript-disclosures/21-0078r2).

\section{REFERENCES}

[1] Gale SA, Acar D, Daffner KR (2018) Dementia. Am J Med 131, 1161-1169.

[2] Bessey LJ, Walaszek A (2019) Management of behavioral and psychological symptoms of dementia. Curr Psychiatry Rep 21, 66.

[3] Lyketsos CG, Carrillo MC, Ryan JM, Khachaturian AS, Trzepacz P, Amatniek J, Cedarbaum J, Brashear R, Miller DS (2011) Neuropsychiatric symptoms in Alzheimer's disease. Alzheimers Dement 7, 532-539.

[4] Kales HC, Gitlin LN, Lyketsos CG (2015) Assessment and management of behavioral and psychological symptoms of dementia. BMJ 350, h369.

[5] Feast A, Orrell M, Charlesworth G, Melunsky N, Poland F, Moniz-Cook E (2016) Behavioural and psychological symptoms in dementia and the challenges for family carers: Systematic review. Br J Psychiatry 208, 429-434.

[6] Matsuoka T, Manabe T, Akatsu H, Hashizume Y, Yamamoto S, Ogawa N, Kanesaka T, Taniguchi C, Yamamoto T, Mizukami K (2019) Factors influencing hospital admission among patients with autopsy-confirmed dementia. Psychogeriatrics 19, 255-263.

[7] Cerejeira J, Lagarto L, Mukaetova-Ladinska EB (2012) Behavioral and psychological symptoms of dementia. Front Neurol 3, 73.

[8] Zdanys KF, Carvalho AF, Tampi RR, Steffens DC (2016) The treatment of behavioral and psychological symptoms of dementia: Weighing benefits and risks. Curr Alzheimer Res 13, 1124-1133.

[9] Nagata T, Kobayashi N, Shinagawa S, Yamada H, Kondo K, Nakayama K (2014) Plasma BDNF levels are correlated with aggressiveness in patients with amnestic mild cognitive impairment or Alzheimer disease. J Neural Transm (Vienna) 121, 433-441.

[10] Nagata T, Kobayashi N, Ishii J, Shinagawa S, Nakayama R, Shibata N, Kuerban B, Ohnuma T, Kondo K, Arai H, Yamada H, Nakayama K (2015) Association between DNA methylation of the BDNF promoter region and clinical presentation in Alzheimer's disease. Dement Geriatr Cogn Dis Extra 5, 64-73.

[11] McDermott CL, Gruenewald DA (2019) Pharmacologic management of agitation in patients with dementia. Curr Geriatr Rep 8, 1-11.

[12] Jost BC, Grossberg GT (1996) The evolution of psychiatric symptoms in Alzheimer's disease: A natural history study. J Am Geriatr Soc 44, 1078-1081.

[13] Cipriani G, Vedovello M, Nuti A, Di Fiorino M (2011) Aggressive behavior in patients with dementia: Correlates and management. Geriatr Gerontol Int 11, 408-413.

[14] Ballard CG, Gauthier S, Cummings JL, Brodaty H, Grossberg GT, Robert P, Lyketsos CG (2009) Management of agitation and aggression associated with Alzheimer disease. Nat Rev Neurol 5, 245-255.

[15] Fransquet PD, Lacaze P, Saffery R, McNeil J, Woods R, Ryan J (2018) Blood DNA methylation as a potential biomarker of dementia: A systematic review. Alzheimers Dement 14, 81-103.

[16] Kobayashi N, Shinagawa S, Nagata T, Shimada K, Shibata N, Ohnuma T, Kasanuki K, Arai H, Yamada H, Nakayama K, Kondo K (2016) Development of biomarkers based on DNA methylation in the NCAPH2/LMF2 promoter region for diagnosis of Alzheimer's disease and amnesic mild cognitive impairment. PLoS One 11, e0146449.

[17] Kobayashi N, Shinagawa S, Nagata T, Shimada K, Shibata N, Ohnuma T, Kasanuki K, Arai H, Yamada H, Nakayama K, Kondo K (2016) Usefulness of DNA methylation levels in COASY and SPINT1 gene promoter regions as biomarkers in diagnosis of Alzheimer's disease and amnestic mild cognitive impairment. PLoS One 11, e0168816.

[18] Kobayashi N, Shinagawa S, Niimura H, Kida H, Nagata T, Tagai K, Shimada K, Oka N, Shikimoto R, Noda Y, Nakajima S, Mimura M, Shigeta M, Kondo K (2020) Increased blood COASY DNA methylation levels a potential biomarker for early pathology of Alzheimer's disease. Sci Rep 10, 12217.

[19] Feil R, Fraga MF (2012) Epigenetics and the environment: Emerging patterns and implications. Nat Rev Genet 13, 97-109.

[20] Horvath S (2013) DNA methylation age of human tissues and cell types. Genome Biol 14, R115.

[21] Uno K, Kikuchi Y, Iwata M, Uehara T, Matsuoka T, Sumiyoshi T, Okamoto Y, Jinno H, Takada T, FurukawaHibi Y, Nabeshima T, Miyamoto Y, Nitta A (2016) Decreased DNA methylation in the Shati/Nat81 promoter in both patients with schizophrenia and a methamphetamineinduced murine model of schizophrenia-like phenotype. PLoS One 11, e0157959.

[22] Reya T, Clevers H (2005) Wnt signalling in stem cells and cancer. Nature 434, 843-850.

[23] Butler MT, Wallingford JB (2017) Planar cell polarity in development and disease. Nat Rev Mol Cell Biol 18, 375-388.

[24] Kuhl M, Sheldahl LC, Park M, Miller JR, Moon RT (2000) The Wnt/Ca2+pathway: A new vertebrate Wnt signaling pathway takes shape. Trends Genet 16, 279-283. 
[25] Kohn AD, Moon RT (2005) Wnt and calcium signaling: Beta-catenin-independent pathways. Cell Calcium 38, 439-446.

[26] Prasad CP, Manchanda M, Mohapatra P, Andersson T (2018) WNT5A as a therapeutic target in breast cancer. Cancer Metastasis Rev 37, 767-778.

[27] Park SY, Kang MJ, Han JS (2018) Interleukin-1 beta promotes neuronal differentiation through the Wnt5a/RhoA/ JNK pathway in cortical neural precursor cells. Mol Brain 11, 39 .

[28] Li Z, Zhang K, Li X, Pan H, Li S, Chen F, Zhang J, Zheng Z, Wang J, Liu H (2018) Wnt5a suppresses inflammation-driven intervertebral disc degeneration via a TNF-alpha/NF-kappaB-Wnt5a negative-feedback loop. Osteoarthritis Cartilage 26, 966-977.

[29] Su F, Bai F, Zhang Z (2016) Inflammatory cytokines and Alzheimer's disease: A review from the perspective of genetic polymorphisms. Neurosci Bull 32, 469-480.

[30] Holmgren S, Hjorth E, Schultzberg M, Larksater M, Frenkel D, Tysen-Backstrom AC, Aarsland D, Freund-Levi Y (2014) Neuropsychiatric symptoms in dementia-a role for neuroinflammation? Brain Res Bull 108, 88-93.

[31] Hashioka S, Wu Z, Klegeris A (2020) Glia-driven neuroinflammation and systemic inflammation in Alzheimer's disease. Curr Neuropharmacol, doi: 10.2174/1570159X18666 201111104509

[32] McKhann G, Drachman D, Folstein M, Katzman R, Price D, Stadlan EM (1984) Clinical diagnosis of Alzheimer's disease: Report of the NINCDS-ADRDA Work Group under the auspices of Department of Health and Human Services Task Force on Alzheimer's Disease. Neurology 34, 939-944.

[33] Roman GC, Tatemichi TK, Erkinjuntti T, Cummings JL, Masdeu JC, Garcia JH, Amaducci L, Orgogozo JM, Brun A, Hofman A, et al. (1993) Vascular dementia: Diagnostic criteria for research studies. Report of the NINDS-AIREN International Workshop. Neurology 43, 250-260.

[34] O'Brien JT, Thomas A (2015) Vascular dementia. Lancet 386, 1698-1706.

[35] McKeith IG, Boeve BF, Dickson DW, Halliday G, Taylor JP, Weintraub D, Aarsland D, Galvin J, Attems J, Ballard CG, Bayston A, Beach TG, Blanc F, Bohnen N, Bonanni L, Bras J, Brundin P, Burn D, Chen-Plotkin A, Duda JE, ElAgnaf O, Feldman H, Ferman TJ, Ffytche D, Fujishiro H, Galasko D, Goldman JG, Gomperts SN, Graff-Radford NR, Honig LS, Iranzo A, Kantarci K, Kaufer D, Kukull W, Lee VMY, Leverenz JB, Lewis S, Lippa C, Lunde A, Masellis M, Masliah E, McLean P, Mollenhauer B, Montine TJ, Moreno E, Mori E, Murray M, O'Brien JT, Orimo S, Postuma RB, Ramaswamy S, Ross OA, Salmon DP, Singleton A, Taylor A, Thomas A, Tiraboschi P, Toledo JB, Trojanowski JQ, Tsuang D, Walker Z, Yamada M, Kosaka K (2017) Diagnosis and management of dementia with Lewy bodies: Fourth consensus report of the DLB Consortium. Neurology 89, 88-100.

[36] Rascovsky K, Hodges JR, Knopman D, Mendez MF, Kramer JH, Neuhaus J, van Swieten JC, Seelaar H, Dopper EG, Onyike CU, Hillis AE, Josephs KA, Boeve BF, Kertesz A, Seeley WW, Rankin KP, Johnson JK, Gorno-Tempini ML, Rosen H, Prioleau-Latham CE, Lee A, Kipps CM, Lillo P, Piguet O, Rohrer JD, Rossor MN, Warren JD, Fox NC, Galasko D, Salmon DP, Black SE, Mesulam M, Weintraub
S, Dickerson BC, Diehl-Schmid J, Pasquier F, Deramecourt V, Lebert F, Pijnenburg Y, Chow TW, Manes F, Grafman J, Cappa SF, Freedman M, Grossman M, Miller BL (2011) Sensitivity of revised diagnostic criteria for the behavioural variant of frontotemporal dementia. Brain 134, 2456-2477.

[37] Gorno-Tempini ML, Hillis AE, Weintraub S, Kertesz A, Mendez M, Cappa SF, Ogar JM, Rohrer JD, Black S, Boeve BF, Manes F, Dronkers NF, Vandenberghe R, Rascovsky K, Patterson K, Miller BL, Knopman DS, Hodges JR, Mesulam MM, Grossman M (2011) Classification of primary progressive aphasia and its variants. Neurology 76, 1006-1014.

[38] Litvan I, Agid Y, Calne D, Campbell G, Dubois B, Duvoisin RC, Goetz CG, Golbe LI, Grafman J, Growdon JH, Hallett M, Jankovic J, Quinn NP, Tolosa E, Zee DS (1996) Clinical research criteria for the diagnosis of progressive supranuclear palsy (Steele-Richardson-Olszewski syndrome): Report of the NINDS-SPSP international workshop. Neurology 47, 1-9.

[39] Mori E, Ishikawa M, Kato T, Kazui H, Miyake H, Miyajima M, Nakajima M, Hashimoto M, Kuriyama N, Tokuda T, Ishii K, Kaijima M, Hirata Y, Saito M, Arai H, Japanese Society of Normal Pressure H (2012) Guidelines for management of idiopathic normal pressure hydrocephalus: Second edition. Neurol Med Chir (Tokyo) 52, 775-809.

[40] Folstein MF, Folstein SE, McHugh PR (1975) "Mini-mental state". A practical method for grading the cognitive state of patients for the clinician. J Psychiatr Res 12, 189-198.

[41] Cummings JL, Mega M, Gray K, Rosenberg-Thompson S, Carusi DA, Gornbein J (1994) The Neuropsychiatric Inventory: Comprehensive assessment of psychopathology in dementia. Neurology 44, 2308-2314.

[42] Hollingworth P, Hamshere ML, Moskvina V, Dowzell K, Moore PJ, Foy C, Archer N, Lynch A, Lovestone S, Brayne C, Rubinsztein DC, Lawlor B, Gill M, Owen MJ, Williams $\mathrm{J}$ (2006) Four components describe behavioral symptoms in 1,120 individuals with late-onset Alzheimer's disease. $J$ Am Geriatr Soc 54, 1348-1354.

[43] Landgrave-Gomez J, Mercado-Gomez O, Guevara-Guzman R (2015) Epigenetic mechanisms in neurological and neurodegenerative diseases. Front Cell Neurosci 9, 58.

[44] Poon CH, Tse LSR, Lim LW (2020) DNA methylation in the pathology of Alzheimer's disease: From gene to cognition. Ann N Y Acad Sci 1475, 15-33.

[45] Harris CJ, Scheibe M, Wongpalee SP, Liu W, Cornett EM, Vaughan RM, Li X, Chen W, Xue Y, Zhong Z, Yen L, Barshop WD, Rayatpisheh S, Gallego-Bartolome J, Groth M, Wang Z, Wohlschlegel JA, Du J, Rothbart SB, Butter F, Jacobsen SE (2018) A DNA methylation reader complex that enhances gene transcription. Science 362, 1182-1186.

[46] Inestrosa NC, Tapia-Rojas C, Lindsay CB, Zolezzi JM (2020) Wnt signaling pathway dysregulation in the aging brain: Lessons from the Octodon degus. Front Cell Dev Biol 8, 734 .

[47] Inestrosa NC, Varela-Nallar L (2015) Wnt signalling in neuronal differentiation and development. Cell Tissue Res 359, 215-223.

[48] Inestrosa NC, Arenas E (2010) Emerging roles of Wnts in the adult nervous system. Nat Rev Neurosci 11, 77-86.

[49] Tang M, Miyamoto Y, Huang EJ (2009) Multiple roles of beta-catenin in controlling the neurogenic niche for midbrain dopamine neurons. Development 136, 2027-2038. 